\title{
DESAFIOS DA EDUCAÇÃO: RELAÇÕES DE GÊNERO E SUJEITOS LGBT
}

\author{
Samira de Moraes Maia Vigiano \\ Maria Hermínia Lages Fernandes Laffin \\ Universidade Federal de Santa Catarina (UFSC), Florianópolis, Santa \\ Catarina, Brasil
}

Resumo: No presente artigo desenvolve-se um debate de gênero e educação a partir da análise do tema da violência, com vistas a compreender a singularidade e a funcionalidade do espaço escolar na experiência de vida de sujeitos LGBT, especialmente referente ao exercício da cidadania e da garantia do direito humano à educação. Ainda, reflete-se sobre os desafios da educação e do currículo sob a perspectiva das relações de gênero e sexualidade de pessoas LGBT. $\mathrm{O}$ artigo respalda-se teoricamente em Butler, Bourdieu, Foucault, Giroux, Laffin, Louro, Miskolci, Scott e Silva. Como resultado do estudo, apontam-se as invisibilidades vivenciadas pelos sujeitos, em possibilidades para um diálogo que vise à inclusão, o respeito e a permanência nos espaços escolares.

Palavras-chave: Gênero. Educação. Sujeitos LGBT. Violência.

INTRODUÇÃO

O artigo em questão apresenta dados da pesquisa de doutorado em educação em andamento no Programa de Pós-graduação da Universidade Federal de Santa Catarina. A pesquisa tem como objetivo situar elementos de determinados processos de exclusão vivenciados no espaço escolar por parte de sujeitos auto identificados como - lésbicas, gays, bixessuais e 
transgêneros, travestis ou transexuais - LGBT. Nesse sentido, trata-se de um artigo que lança mão dos meandros do debate entre gênero e educação a partir do escrutínio do tema da violência homofóbica (utilizarei o termo homofobia, mas busco englobar todas as formas de violências relacionadas aos sujeitos LGBT, como por exemplo, a homo/lesbo/transfobia), com vistas a compreender a singularidade e a funcionalidade do espaço escolar na experiência de vida de sujeitos LGBT, especialmente referente ao exercício da cidadania e da garantia do direito à educação. Ao dialogar com as questões de gênero e sexualidade, busquei destacar os aspectos que em geral excluem esses sujeitos dos processos de escolarização, como o bullying, as violências (físicas e simbólicas) e a falta de aceitação nos espaços institucionalizados.

No decorrer da escrita, no momento da abordagem de alguns temas da tese, foi necessário contextualizar historicamente como esses processos foram se corporificando através dos tempos, e um dos assuntos que se apresentou como pertinente para o debate se relaciona às questões curriculares e às demais ações que envolvem o processo de escolarização.

Posto isso, considero que a discussão proposta é original e relevante, sobretudo quando se reflete acerca da onda conservadora que assola na atualidade o Brasil e, particularmente, o sistema educacional. É fato que cada vez é mais difícil pautar sobre gênero e sexualidade nas escolas, principalmente depois que setores conservadores da sociedade assumiram uma postura mediante a chave analítica equivocada intitulada de ideologia de gênero.

É no movimento em que há a dificuldade de aceitar o/a outro/a como diferente, que desejo demonstrar que "a diferença não é uma característica natural: ela é discursivamente produzida" (SILVA, 2000, p. 89), ou seja, além de ela ser construída, ela também foi naturalizada. Dessa forma, este artigo objetiva compreender os desafios da educação sob a perspectiva das relações de gênero e sexualidade, principalmente no que se refere aos sujeitos LGBT, para tanto, busquei como foco o currículo e suas múltiplas facetas. Justifico a escolha pelo fato de que a sexualidade e o gênero estão, mais do que nunca, no centro dos discursos, e começam a provocar um certo ruído por onde passam (LOURO, 2000).

Na busca de problematizar tais temáticas, percebi como necessário abordar os seguintes assuntos: a função do currículo, questões de gênero e sexualidade, as violências e a necessidade do acolhimento, dividindo o artigo em: introdução, aspectos do currículo e das violências, o acolhimento como possibilidade educativa, e as considerações finais. Sendo assim, respaldeime em autores e autoras que contribuem para o debate, tais como: Butler, Bourdieu, Foucault, Giroux, Laffin, Louro, Miskolci, Scott e Silva. 
Em Butler (2001), Louro (1997; 2000; 2001) e Scott (1995) contextualizo conceitos de gênero e sexualidade; em Giroux (1986; 2005) e Silva (2000; 2010; 2011) busco os aspectos do currículo; de Bourdieu $(1998 ; 2008)$ e Foucault (1993) trago a compreensão das violências e das relações de poder; com Miskolci (2005) dialogo sobre os conceitos de espaço escolar e os sujeitos LGBT, e Laffin (2007) leva-me a perceber como o acolhimento pode ser um fator agregador para a ação docente, principalmente no que tange à inclusão e permanência desses sujeitos.

\section{CURRÍCULO E SUJEITOS LGBT: VIOLÊNCIAS INSTITUCIONALIZADAS}

Para falar sobre currículo é necessário discutir e trabalhar as relações de gênero e sexualidade dos alunos e alunas LGBT? É importante abordar gênero e sexualidade na sala de aula? Estas são perguntas que permeiam as discussões dos currículos e dos planos de educação. Há nesse debate um jogo de forças que deseja manter a ótica excludente dos currículos, retirando temáticas que fazem parte da construção das identidades de todos os sujeitos. A discussão de gênero e sexualidade baseia-se em uma construção histórica da desigualdade entre homens e mulheres, que faz parte de nossa sociedade há décadas, e, mesmo assim, ainda existem fatores que se colocam como impeditivos desses debates.

Os estudos de gênero têm demonstrado que há uma forma esquemática que se cristaliza no pensamento dos seres humanos. A linguagem acaba sendo um desafio constante na desconstrução de um padrão que tende a desvalorizar os sujeitos LGBT.

Mesmo mediante tantos esforços para desconstruir padrões sexistas, homofóbicos e machistas, os estudos de gênero esbarram em práticas que visam ratificar uma sociedade que exclui o"diferente". A escola, assim como as demais instituições sociais, faz parte dessa construção. Ela está permeada por relações de dominação, opressão e poder explicitamente apresentadas nas formulações curriculares. Na verdade, a escola se pauta em modelos ideais de masculinidades e feminilidades e deseja que seus alunos e alunas cheguem o mais perto desses modelos, ocultando tudo que lhe parece fora da ordem vigente. "O menino ou a menina que se revela diferente não é estranho em si mesmo" (MISKOLCl, 2005, p. 17). É o educador, a educadora, os colegas ou as colegas que os colocam dentro de uma forma que se apresenta como "esquisita" (MISKOLCl, 2005).

O que se representa nas instituições de ensino é tão complexo e violento, que faz com que os sujeitos LGBT busquem a aceitação, e para isso, "escodam" sua identidade ou sua orientação sexual. Esse processo de 
"ocultamento de determinados sujeitos pode ser flagrantemente ilustrado pelo silenciamento da escola em relação às sexualidades (LOURO, 2001).

Não é à toa que recentemente tramitam no congresso nacional algumas propostas de leis que visam retirar o debate de gênero da escola. Essa retirada de certos conteúdos relacionados ao gênero leva ao fortalecimento de práticas de exclusão, principalmente com os alunos e alunas LGBT. Isso porque a retirada dos conceitos de gênero e consequentemente de sexualidade pode contribuir para que os currículos sejam cada vez mais excludentes.

Entendo que o conceito de gênero se institui por meio de concepções históricas contemporâneas reforçadas pelo movimento feminista. "As feministas não somente começaram a encontrar uma voz teórica própria; elas também encontram aliados científicos e políticos. É dentro deste espaço que nós devemos articular o gênero como categoria de análise" (SCOTT, 1995, p. 14). De acordo com Scott (1995), gênero é uma categoria de análise sociológica e histórica que permite compreender que as relações sociais são estabelecidas pelos saberes, ou seja, são os saberes que dão significados às diferenças sociais e corporais, entretanto, estes saberes não são absolutos, e modificam-se em cada cultura. "Gênero é, segundo esta definição, uma categoria social imposta sobre um corpo sexuado"(SCOTT, 1995, p. 05).

Sobre sexualidade, Jeffrey Weeks (2000, p. 40) descreve que ela é"[...] na verdade, 'uma construção social', uma invenção histórica, a qual, naturalmente, tem base nas possibilidades do corpo: o sentido e o peso que lhe atribuímos são, entretanto, modelados em situações sociais concretas". Desse modo, "a sexualidade é um elemento determinante na constituição dos sujeitos, tão necessário quanto o ar que respiramos" (PRADO; MACHADO, 2008, p. 15).

Os conceitos de sexualidade e gênero exibem uma gama de possibilidades destoantes da heteronormatividade, mas "são interdependentes" (LOURO, 1997, p. 49), sendo que "o gênero é o primeiro modo de dar significado às relações de poder" (SCOTT, 1995, p. 14). "Na realidade, o poder é um feixe de relações mais ou menos organizado, mais ou menos piramidalizado, mais ou menos coordenado" (FOUCAULT, 1993, p. 141).

Muito embora haja uma constante propagação de que o que se deseja ao falar de gênero na sala de aula é fazer uma doutrinação denominada de ideologia de gênero, os estudos de gênero não desejam isso, já que o termo ideologia de gênero nem está presente nas teorias de gênero. Essa expressão foi criada ou inventada por um fundamentalismo religioso que buscou cunhar uma compreensão equivocada do que é gênero, enfatizando que os estudos de gênero na escola podem fazer com que haja uma doutrinação de valores homossexuais na "mente" dos/as alunos e alunas (FURLANI, 2016). O 
fundamentalismo religioso refere-se ao movimento religioso e conservador que iniciou nos Estados Unidos, no início do século XX, pelos seguidores do protestantismo, em que o objetivo central era de inserir as palavras bíblicas como fundamentais para guiar a vida de todos os seres humanos.

Na atualidade, esse fundamentalismo veio à tona com o fortalecimento da bancada de deputados cristãos no Congresso Nacional Brasileiro, que se uniram a outros deputados da esfera conservadora a fim de incutir "velhos" princípios conservadores que delimitam o lugar das mulheres, dos homens e dos homossexuais (FURLANI, 2016). Todavia, o que de fato os estudos de gênero desejam é que as diferenças sejam aceitas dentro de suas pluralidades, e que o respeito às diversidades faça parte do cotidiano, e que, com isso, todos e todas possam ter seus direitos garantidos.

Tal debate se apresenta demasiadamente pertinente, porque as distinções dos gêneros levaram a condições de subalternidades entre os indivíduos, e isso fortaleceu processos sociais excludentes, principalmente para os/as que se encontram fora da norma.

Naturalizou-se o argumento de que homens e mulheres são biologicamente distintos e, por isso, inferiorizaram-se as mulheres. Nesse processo de naturalização coube a cada um desempenhar seu papel na sociedade, e aqueles/as que não se localizam em nenhum desses papéis não devem ser reconhecidos/as. Essa é uma maneira de afirmar a distinção e justificar a desigualdade e a exclusão, e tal ação "tende a transformar[-se] em um corpo doutrinal de normas e fórmulas explícitas e explicitamente ensinadas, mais frequentemente negativas que positivas" (BOURDIEU, 2008, p. 66).

O conjunto de normas e prescrições que a sociedade e a cultura dita para cada um dos corpos influencia diretamente a exclusão dos sujeitos LGBT. Mesmo que as bases das diferenças sexuais sejam determinadas pelos padrões impostos, sua atribuição está pautada em expectativas de masculinidades e feminilidades. Tais expectativas recaem diretamente na formação dos sujeitos e consequentemente nos currículos escolares.

Embora as mudanças sejam recorrentes desde o século $X X$, ainda são "delimitados" os espaços que a população LGBT deve frequentar. Mesmo que não ocorram explicitamente, as padronizações e os valores socioculturais cerceiam os espaços dos diversos gêneros. Este tipo de coerção imposto pelos grupos sociais serve para que se mantenha o comportamento esperado pelo padrão estabelecido para cada um dos gêneros (LOURO, 2001), desencadeando ações preconceituosas e violentas.

Essa depreciação se dá inicialmente pelo policiamento do gênero. A discriminação faz com que a escola torne-se parte de uma rejeição social a 
todos/as aqueles/as que não vivem de forma hegemônica. E o currículo, que poderia ser uma ferramenta de "soltura" das imposições heteronormativas, acaba sendo um fortalecedor do modelo binário. Sendo assim, "a instituição escolar tende a invisibilizar a sexualidade em um jogo de pressupostos, inferências não-apresentadas e silêncios. Pressupõe-se, por exemplo, que a sexualidade é um assunto privado ou, ao menos, restrito ao lado de fora da escola" (MISKOLCl, 2005, p. 17).

Mesmo que a escola tenha tentando "fugir" do debate de gênero e sexualidade, os temas têm se apresentado com frequência nos enfoques dados pela mídia, em novelas, cinema, programas de auditório, propagandas e revistas, certamente por conta das lutas dos movimentos sociais que buscam a igualdade e reconhecimento, buscando quebrar com aqueles estereótipos pejorativos pelos quais eram retratados os sujeitos LGBT nos diversos meios de comunicação. É possível que essa exposição midiática tenha requerido da escola uma nova postura frente às demandas trazidas pelos estudantes. Todavia, a falta de formação conduz os/as docentes a atuarem conforme as perspectivas que aprenderam no seu cotidiano, trazendo desses aprendizados influências culturais e crenças religiosas que retratam os padrões ocidentais mais excludentes. Tais padrões estão permeados por valores de dominação e controle tipicamente masculinos, que mesmo atualmente se modelam em comportamentos sexistas e homofóbicos.

A propagação de valores sexistas pode ter relação com a falta de enfoque dessas questões nos currículos das licenciaturas, o que leva os professores e as professoras a uma defasagem em seu processo formativo, que refletirá em posturas meramente embasadas no senso comum, acabando, muitas vezes, por reagir de forma preconceituosa e discriminatória com os alunos e alunas LGBT.

De todo modo, a universidade tem sido chamada à responsabilidade pela discussão do tema de gênero e de sexualidade, focando principalmente na inclusão das chamadas "minorias". Isso implica em uma abertura para a discussão, para posicionarem-se politicamente as novas demandas dos sujeitos sociais que desejam também seu espaço no currículo. Conceitos como alteridade, equidade, heteronormatividade, diversidades fomentam as novas demandas para os espaços de formação docente.

As discussões sobre a igualdade de gênero e a aceitação da diversidade fazem parte da Constituição Brasileira desde 1988 e se consolidam na Lei de Diretrizes e Bases da Educação Nacional - LDB/1996. Ainda nos anos 1990 é iniciada a discussão para que haja a incorporação nos Parâmetros Curriculares (PCN) dos temas transversais de orientação sexual e pluralidade 
cultural. Ao utilizar o termo orientação sexual, os PCN desejavam fazer com que a escola abordasse questões referentes à sexualidade, buscando criar ações de respeito entre os alunos e alunas, além de diminuir a discriminação existente na sala de aula. De acordo com os PCN:

A escola, ao definir o trabalho com Orientação Sexual como uma de suas competências, o incluirá no seu projeto educativo. Isso implica uma definição clara dos princípios que deverão nortear o trabalho de Orientação Sexual e sua clara explicitação para toda a comunidade escolar envolvida no processo educativo dos alunos. Esses princípios determinarão desde a postura diante das questões relacionadas à sexualidade e suas manifestações na escola, até a escolha de conteúdos a serem trabalhados junto aos alunos. A coerência entre os princípios adotados e a prática cotidiana da escola deverá pautar todo o trabalho. (BRASIL, 1999, p. 299).

Já o Plano Nacional de Educação - PNE, que esteve em vigor entre 2001-2010, trouxe importantes metas para a educação superior, tendo em vista a inclusão da temática de gênero nas Diretrizes Curriculares dos cursos de licenciaturas. Todavia, a inclusão da temática de gênero no PNE é limitada e não contempla algumas questões importantes, como a transversalização de gênero, em todos os currículos da formação profissional. Segundo Carvalho (2013, p. 04), ao transversalizar as questões sobre gênero no currículo é importante destacar que essas questões existem como categorias de análise social, como um tema gerador e como um conteúdo de todas as disciplinas e cursos, implicando problematizar a violência de gênero, os estudos feministas e as desigualdades sociais existentes nas relações de gênero.

O Plano Nacional de Educação - PNE: 2014-2024, em vigor, aponta para a importância da implementação de políticas educacionais que visem combater todas as formas de discriminação existentes nos espaços escolares. Esse documento destaca a necessidade da promoção dos direitos humanos e da diversidade na educação do Brasil.

É importante situar também o levantamento realizado pelo Instituto Nacional de Estudos e Pesquisas Educacionais Anísio Teixeira - INEP (BRASIL, 2009), que identificou juntamente com outras instituições as problemáticas de gênero na educação do Brasil, sendo elas: as desigualdades persistentes entre as mulheres brasileiras; permanência ou não e desempenho por parte dos meninos e meninas, adolescentes e jovens brasileiros, em especial, os negros; a manutenção de uma educação sexista, racista, homofóbica e discriminatória; a valorização profissional baseada nos modelos patriarcais; a desvalorização dos/as profissionais da educação básica; a falta de acesso a uma educação infantil de qualidade (BRASIL, 2009). 
Vale ressaltar que o mesmo estudo apresentou como um problema na educação a não aceitação do Kit Escola sem Homofobia e o fim da distribuição de materiais educativos federais relacionados com o Programa de Saúde e Prevenção na Escola (BRASIL, 2009).

Mesmo diante de tantas demandas é necessário que seja levado em consideração o fato de que a escola foi historicamente baseada em proposições herdadas da psicologia da aprendizagem, que tem sua raiz na biologia e na teoria evolucionista darwinista. Essa herança faz com que o entendimento das diversidades se ordene dentro de uma hierarquia de desenvolvimento funcional.

No entanto, mesmo que as bases da escola tenham sido cunhadas em uma padronização que se norteie nas hierarquias, muito tempo se passou, e houve uma série de leis e diretrizes que deveriam ter proporcionado uma nova compreensão de educação e alicerçado a formação docente. Miskolci (2005) indica que tais questões e legislações visam ou visariam fornecer elementos para a discussão de convenções, tentando demonstrar como na sociedade ainda são impostas barreiras à expressão de identidades.

Diante das constantes transformações nas relações vividas em sociedade e das informações divulgadas com mais rapidez, a escola acaba por passar por profundas críticas sobre sua função social, e, com isso, cada vez mais se debate sua função por meio de uma perspectiva reflexiva, crítica e transformadora, fazendo com que o currículo venha a ser a "porta de entrada" para o debate de gênero, sexualidade e respeito às diversidades. Entretanto, ele ainda está permeado por padrões que não visam incluir tais discussões: "o currículo da escola está baseado na cultura dominante: ele se expressa na linguagem dominante, ele é transmitido através do código cultural dominante" (SILVA, 2011, p. 35).

Os modelos e propostas curriculares definem as práticas docentes, o que a escola tem que fazer (ou reproduzir) e como os professores e as professoras devem agir para alcançar objetivos avaliativos traçados a partir de habilidades técnicas. Embora considerando essa problemática, a função do currículo, de acordo com Giroux (1986), é de levar a escola a exercer seu papel como uma esfera pública democrática, na qual os alunos e alunas são levados a participarem de atividades emancipadoras e críticas. Por meio dessas atividades emancipatórias, tanto os professores e professoras, quanto alunos e alunas devem ser guiados a questionarem ativamente todas as práticas e conteúdos previamente determinados, e assim negociarem a relação entre a teoria e a prática, "entre a análise crítica e o senso comum e entre a aprendizagem e a transformação social." (GIROUX, 2005, p. 135). 
Os conteúdos disciplinares contidos nos currículos são elementos que contribuem para se pensar as atividades e também se configuram nas relações sociais ao longo das tarefas solicitadas pelos professores e professoras (SACRISTÁN, 2000). A teoria, desse modo, acaba sendo um instrumento de estudo para o reconhecimento das diversas formações sociais e para a "descoberta de melhores formas de conhecimento e modos de intervenção para contrapor aos desafios de um autoritarismo crescente ou de um pessimismo fabricado" (GIROUX, 2005, p.135).

Sendo assim, o conteúdo é a condição lógica do ensino, e o currículo é, antes de tudo, uma seleção cultural estruturada sob as chaves psicopedagógicas dessa cultura que se oferece como projeto para a instituição escolar (SACRISTÁN, 2000). Ou seja, apesar de, em geral, ser pensado inicialmente para suprir essa função massificadora, e sendo proveniente de uma cultura dominante, pouco socializadora, e um artefato de poder, o currículo pode ter uma função emancipadora; e pode ainda ser um importante aliado para os debates de gênero, sexualidade e diversidade, de forma a subsidiar a formulação de políticas e estratégias de ação que promovam, a médio e longo prazo, a redução das desigualdades, o respeito e a própria educação para a diversidade (MAZZON, 2009).

Segundo Giroux (1986) a escola deve ser crítica a ponto de desmascarar as desigualdades sociais e apresentar explicitamente as possibilidades de resistência, considerando o/a docente como um/a intelectual transformador/a. Isso tendo em vista que a escola é um espaço político, e a sua "natureza política decorre da sua capacidade de fazer imaginar um mundo diferente e de fazer agir de modo diferente e este é o seu principal contributo para qualquer noção viável de educação para a cidadania" (GIROUX, 2005, p. 135).

Mas, como fazer essa transformação quando não há formação? Como educar para a cidadania com um currículo que não inclui todos e todas? Mais uma vez, alguns questionamentos surgem e se revelam como preocupações determinantes no processo de aprendizagem, levando-me a refletir sobre o fato de que "é importante ver o currículo não apenas como sendo constituído de 'fazer coisas' mas também vê-lo como fazendo coisas às pessoas" (SILVA, 2011, p. 194).

Embora as práticas pedagógicas permeadas pelos currículos tenham ampliado seus debates sobre as diversidades, ainda há uma série de questões que permanecem obscuras. Há até um crescimento no enfoque sobre as mulheres, sobre o racismo e até mesmo sobre as deficiências, entretanto, os 
sujeitos LGBT são postos em situações de invisibilidades, seja no que se refere às suas necessidades, ou seja no que se refere ao currículo.

\section{EDUCAÇÃO, VIOLÊNCIAS E ACOLHIMENTO}

Em pleno século XXI debater a questão da violência enraizada na sociedade ainda é um tema polêmico, mesmo considerando que essa violência deixa grandes marcas em quem as sofre. Essa reflexão nos demonstra que nem tudo está tranquilo para quem não corresponde às normas conservadoras sobre gênero.

A violência é diária e a escola faz parte desse histórico. Nesse espaço, a violência simbólica está tão naturalizada que muitas vezes nem é entendida como tal. É como se ela estivesse na origem do ser humano, algo que parece ser genuíno no senso comum e que se propaga sem contestação. Esse senso comum é proveniente de crenças e valores que, quando naturalizados e cristalizados, criam e propagam os preconceitos. Em uma sociedade em que se personificam perfis e estereótipos, os homossexuais e as pessoas com identidades de gênero divergentes representam a contraordem, sendo passíveis de punição, violências e desprezos, como se fossem não humanos.

As múltiplas culturas que constroem as identidades são marcadas pelas influências externas, seja nas representações literárias, ou nas descrições de uma normatividade inclusa em nosso imaginário, levando a um "julgamento" do que é aceito como correto. É notável, dessa forma, que tais construções definam e norteiem comportamentos e posturas, e resultem em um padrão.

A escola como um espaço social diverso personifica esse padrão, mesmo que lá seja um local onde convivem pessoas com diferentes crenças, etnias, culturas, classes sociais, raças e gêneros. Essa diversidade deveria ser motivo de troca de saberes e crescimento constante, todavia, por diversas vezes, ela é desencadeadora de sentimentos negativos e excludentes com aqueles/as que não se legitimam nas normas socialmente impostas. A intolerância, nesses casos, acaba sendo uma ação frequente, demonstrando que a instituição escolar não é um lugar que aceita todos e todas.

Dentro desse contexto, compreendo que a escola é a instituição que se fundamenta pela lógica do estado e, como tal, funciona como um mecanismo de coerção e adequação social, possuindo "currículo, regulamentos, instrumentos de avaliação e ordenamento que dividem, hierarquizam, subordinam, legitimam ou desqualificam os sujeitos" (LOURO, 1997, p. 84). Nesse viés, as pessoas LGBT acabam por ficar à margem das 
discussões e são pouco são referenciadas nos livros didáticos ou em outros aparatos utilizados na educação.

No decorrer dos tempos houve uma ausência nos currículos escolares da temática homossexual ou transgênera (refiro-me a transgêneras como uma espécie de "termo guarda-chuva" que busca englobar todas as pessoas que não se encontram em conformidade com as normas de gênero [LANZ, 2015]), dando a impressão de que a escola tem um falso entendimento de que todos os alunos e as alunas são encaixados nos padrões binários da heterossexualidade, enquadrando-se perfeitamente nas imposições sociais patriarcais e falocêntricas.

A constituição de um currículo pautado nas bases patriarcais foi historicamente determinada por práticas de discursos que objetivam moldar as pessoas conforme uma ideologia definida como a melhor e a culturalmente aceita. Vale considerar de que essa "produção de discursos 'verdadeiros' [...] é um dos problemas fundamentais do ocidente" (FOUCAULT, 1993, p. 128).

O currículo não pode ser mais pensado de forma fechada e única, moldado para apenas repassar o conhecimento científico. A sua função é muito mais abrangente do que simplesmente atender ao sistema econômico ou a relações de produção. O desafio está justamente em como tornar o currículo significativo, tornando-o crítico (GIROUX, 1986), "entendendo que as práticas cotidianas são fornecedoras de indícios para a compreensão das redes complexas que nelas se formam e que as formam" (OLIVEIRA, 2003, p. 135).

Sendo assim, compreender a história do currículo é perceber que ele é um fator de produção de sujeitos, de classe, de raça e de gênero. $O$ currículo, nessa perspectiva, não deve ser visto apenas como a expressão, a representação ou o reflexo de interesses sociais determinados, mas também como produtor de identidades e subjetividades sociais determinadas (SILVA, 2011).

Embora a escola esteja pautada em uma cultura que segrega o diferente, os documentos de referência para as atividades educacionais demonstram que a escola deve ser um espaço acolhedor, que aceite as diferenças, e com múltiplas interlocuções. A priori, o que vemos é que há uma contradição entre as práticas e o que se encontra exposto em alguns documentos norteadores, como o Projeto Político Pedagógico - PPP das instituições de ensino. Esse hiato que separa a teoria da prática evidencia que os documentos norteadores, mesmo que regulamentados, não conseguem "quebrar" a barreira consolidada dos preconceitos. Sendo assim, o silêncio torna-se cúmplice das ações, e quebrar este ciclo não é tarefa fácil, pois a sexualidade e o gênero são alvo da vigilância e do controle sociais (LOURO, 2000). 
"As diferentes instituições e práticas sociais são constituídas pelos gêneros e são, também, constituintes dos gêneros. Essas práticas e instituições 'fabricam' os sujeitos" (LOURO, 1997, p. 25). Essa fabricação invisibilizou os sujeitos LGBT e produziu diversas violências, principalmente simbólicas. Essas violências se traduzem nas pequenas ações do cotidiano escolar, como o não tratamento do casamento homoafetivo, a falta de discussão dos padrões de cores e de famílias, a rejeição do uso do nome social, o cerceamento de espaços públicos, como os banheiros, entre outras.

Justificativas surgem para as desigualdades e para as violências e, em geral, não são desencadeadas apenas pelas diferenças biológicas, mas pelos arranjos sociais (LOURO, 1997) que agem por meio de ações naturais criadas para violentar a fim de dominar progressivamente o corpo de cada um.

O problema é que quando se estabelecem as distinções entre os gêneros, e quando se padronizam papéis sociais, acabam-se projetando preconceitos. A escola tem o papel de "quebrar" com esses preconceitos, em busca da socialização e de amplificação de uma cultura que valorize a diversidade.

As "brincadeiras" feitas nos espaços escolares são carregadas de preconceitos contra negros, mulheres, gays, lésbicas, gordos, indígenas, deficientes, pobres, travestis, entre outros. A diversidade que está na escola raramente é vista como algo positivo, ao contrário, a escola baseia-se em currículos tradicionais e conservadores que não debatem as diferenças. As desigualdades socialmente condicionadas diante da escola e da cultura são injustas com toda uma sociedade em que se proclamam ideais democráticos (BOURDIEU, 1998).

Essa falta de diálogo leva muitos alunos e alunas LGBT à evasão escolar, pois eles e elas não se sentem acolhidos nesse espaço. Laffin (2007, p. 117) define que o acolhimento é um conjunto de ações de cuidado das/ os docentes com uma intencionalidade para com o sujeito e para o ato de conhecimento. Essa intencionalidade se refere a um movimento de provimento de condições para o ato de conhecer, como ação de "mobilização para", e de diálogo no sentido da desmitificação da própria imagem de desvalorização dos alunos e alunas, na sua própria relação com o processo de aprendizagem. O provimento dessas condições pode viabilizar outra relação com o saber. Assim, pensar na possibilidade do acolhimento como uma prática que vise superar as dificuldades de socialização e aceitação nos espaços educacionais é uma forma de proporcionar um novo caminho curricular e educacional para os sujeitos LGBT. 
Viabilizar um currículo acolhedor é criar possibilidades de inclusão e permanência efetiva desses alunos e alunas, já que a experiência de criação e transformação das diferentes relações estabelecidas com os outros e com o mundo reflete-se na relação que cada um/a estabelece com o meio (CHARLOT, 2001, p. 103). Sendo assim, quando a escola lida com as temáticas relacionadas ao corpo, ela se mostra atenta às necessidades, e isso resulta em um "cuidado" com a diversidade e resulta, também, no fato de a escola fazer uso de seu espaço para acolher todos e todas, cumprindo, assim, sua função social e garantindo um dos Direitos Humanos.

Sugerir que o currículo seja acolhedor vai além de dizer que ele tem que conter temáticas que deem sentido para a diversidade, para o gênero ou para a sexualidade, é demonstrar que o currículo se traduz em ações diárias, em atividades conduzidas por meio do olhar às singularidades. É o que alguns teóricos chamam de currículo oculto, pois no processo escolar os sujeitos constroem para além das aprendizagens, aprendem sobre sua constituição, sobre o modo como são pensados em suas capacidades e vivências. "O currículo oculto é constituído por todos aqueles aspectos do ambiente escolar que, sem fazer parte do currículo oficial, explícito, contribuem, de forma implícita, para aprendizagens sociais relevantes" (SILVA, 2010, p. 78).

O currículo oculto pode contribuir para as aprendizagens, mas também pode ajudar no enraizamento de estereótipos. Uma vez que fixos e naturalizados, os estereótipos carregam aspectos negativos e depreciativos. O machismo e a misoginia são aplicados a esses estereótipos e fazem com que a escola fique intrinsicamente comprometida com a manutenção de uma sociedade dividida, e ela faz isso cotidianamente, com a participação ou omissão dos/as docentes (LOURO, 1997). Mas fazer essa manutenção estereotipada não é tarefa fácil, pois "a sexualidade está na escola porque ela faz parte dos sujeitos, ela não é algo que possa ser desligado ou algo do qual alguém possa se despir" (LOURO, 1997, p. 81).

Os resultados da falta de diálogo sobre as questões de gênero e os sujeitos LGBT indicam que o:

[...] preconceito e a discriminação latente nas escolas resultam muitas vezes em situações em que pessoas são humilhadas, agredidas ou acusadas injustamente simplesmente pelo fato de fazerem parte de algum grupo social específico. As práticas discriminatórias no ambiente escolar têm como principais vítimas os alunos, mas atingem também a professores e funcionários. (MAZZON, 2009, p. 40) 
Contudo o espaço escolar pode ser um lócus relevante para o desenvolvimento de uma visão mais aberta, democrática e respeitosa de como lidar com as diferenças que tangem à vida sexual e afetiva.

Desse modo, mesmo com tantos avanços e discussões sobre as diversidades, ainda há uma falta de acolhimento dos alunos e alunas LGBT. A escola ainda está permeada por relações de poder, que não apenas reproduzem as desigualdades de gênero, classe, raça ou etnia, mas também produzem relações hierárquicas. Essas relações são representadas por meio de um currículo monocultural, que causa invisibilidade dos sujeitos que não se enquadram nos padrões e normas que a escola perpetua.

\section{CONSIDERAÇÕES FINAIS}

Compreender os desafios da educação sob a perspectiva das relações de gênero e sexualidade, principalmente no que se refere aos sujeitos LGBT, é traduzir as invisibilidades vivenciadas por essas pessoas em possibilidades para um diálogo que vise à inclusão, ao respeito e à permanência.

Esse diálogo buscou destacar os aspectos que em geral excluem esses sujeitos dos processos de escolarização, como o bullying, as violências (físicas e simbólicas) e a falta de aceitação nos espaços institucionalizados, dando ênfase para o currículo e a ação docente. O bullying, os estereótipos, as brincadeiras que parecem inocentes geram evasões e repetências em alguns/ mas estudantes. É importante discutir a temática de gênero e sexualidade, porque a instituição escolar, de forma explícita ou implícita, por meio do currículo, do Projeto Político Pedagógico e das demais ferramentas do cotidiano escolar ainda se pauta na produção e reprodução das desigualdades.

"Seja homem!": essa é uma das frases que meninos e homens escutam centenas de vezes durante a vida."Deveria ser mais delicada!": também é uma frase que transpassa o cotidiano de mulheres. Esta cobrança incessante por ser homem, ser mulher, por agir como um homem, agir como uma mulher está no centro de muitos problemas sociais. Essas normatizações podem levar muitas pessoas a cometer suicídios, ou à depressão por não se sentirem aceitas na sociedade.

Nesse sentido, as relações de gênero encontram-se imbricadas nas identidades sexuais e sociais dos sujeitos. A sexualidade é atravessada e mensurada por meio de classificações e de padronizações baseadas na hierarquização e na submissão dos gêneros, provocando as mais variadas violências.

Os documentos legais e outros trabalhos constituem-se como um rico material para a ação docente, na perspectiva de despertar uma reflexão sobre 
essas questões. Todavia, essa é uma discussão original, relevante e desafiadora, especialmente quando há uma onda de conservadorismo e de "quebra" de direitos. Essa quebra de paradigmas deve fazer parte do cotidiano educativo, apresentando uma outra forma de demonstrar o que é ser homem e o que é ser mulher, indo além da construção estereotipada da feminilidade e da masculinidade, e buscando por meio do respeito e da equidade transformar a escola em um espaço acolhedor.

Vale ressaltar que as experiências educativas escolares não se referem apenas ao conhecimento científico, mas principalmente às situações vivenciadas no cotidiano e à constituição da subjetividade de cada um de nós.

\section{CHALLENGES OF EDUCATION: GENDER RELATIONS AND LGBT SUBJECTS}

ABSTRACT:This article presents a debate on gender and education based on the analysis of the theme of violence, in order to understand the uniqueness and functionality of the school space in the life experience of LGBT subjects, especially regarding the exercise of citizenship and the guarantee of Human Right to education. Also, it reflects on the challenges of education and the curriculum from the perspective of the relations of gender and sexuality of LGBT people. It is supports theoretically in Butler, Bourdieu, Foucault, Giroux, Laffin, Louro, Miskolci, Scott and Silva. As a result of the study, we point to the invisibilities experienced by the subjects, and to the possibilities for a dialogue that aims at inclusion, respect and permanence in school spaces.

KEYwORDS: Gender. Education. LGBT Subjects. Violence.

\section{DESAFÍOS DE LA EDUCACIÓN: RELACIONES DE GÉNERO Y SUJETOS LGBT}

RESUMEN: Este artículo desarrolla un debate de género y educación a partir del análisis del tema de la violencia, con miras a comprender la singularidad y la funcionalidad del espacio escolar en la experiencia de vida de sujetos LGBT, especialmente en lo que se refiere al ejercicio de la ciudadanía y de la garantía del derecho humano a la educación. Se reflexiona sobre los desafíos de la educación y del currículo desde la perspectiva de las relaciones de género y sexualidad de personas LGBT. Se respalda teóricamente en Butler, Bourdieu, Foucault, Giroux, Laffin, Louro, Miskolci, Scott y Silva. El resultado de este estudio pone de manifiesto las invisibilidades experimentadas 
por los sujetos, en posibilidades para un diálogo que busca la inclusión, el respeto y la permanencia en los espacios escolares.

Palabras claves: Género. Educación. Sujetos LGBT. Violencia.

\section{REFERÊNCIAS}

BOURDIEU, P. A distinção: crítica social do julgamento. São Paulo: EDUSP; Porto Alegre, RS: Zouk, 2008.

BRASIL. Ministério da Educação. Parâmetros Curriculares Nacionais: ensino Fundamental: orientação sexual. Brasília: Ministério da Educação, 1999.

BRASIL. Ministério da Educação. Instituto Nacional de Estudos e Pesquisas Educacionais - INEP. Pesquisa sobre preconceito e discriminação no ambiente escolar: principais resultados. Brasília: MEC; INEP, 2009.

BUTLER, J. Corpos que pesam: sobre os limites discursivos do sexo. In: LOURO, G. L. O corpo educado: pedagogias da sexualidade. Belo Horizonte: Autêntica, 2001.

CARVALHO, M. E. P. de. Informe 1: Inclusão de gênero nos currículos da educação superior no Brasil e na UFPB. In: Relatório PROJETO CAPES/DGU 303/13. João Pessoa: UFPB, 2013.

CHARLOT, B. (Org.). Os jovens e o saber: perspectivas mundiais. Porto Alegre: Artes Médicas, 2001.

FOUCAULT, M. Microfísica do poder. Rio de Janeiro: Graal, 1993.

GIROUX, H. Os professores como intelectuais: rumo a uma pedagogia crítica da aprendizagem. Porto Alegre: Artes Médicas, 1986.

. Qual o papel da pedagogia crítica nos estudos de língua e de cultura? Entrevista com Henry Giroux. Revista Crítica de Ciências Sociais, La Rioja, n., 73, p. 131-143, dez. 2005.

FURLANI, J. "Ideologia de Gênero"? Explicando as confusões teóricas presentes na cartilha. Florianópolis: FAED, UDESC. Top afiliados Laboratório de Estudos de Gênero e Família, 2016.

LAFFIN, M. H. L. F. Reciprocidade e acolhimento na educação de jovens e adultos: ações intencionais na relação com o saber. Educação revisitada, Curitiba, n. 29, p. 101-119, 2007. Disponível em:<http://www.scielo.br/scielo.php?script=sci_arttext\&pid=S0104$-40602007000100008 \&$ lng=en\&nrm=iso $>$ Acesso em: 01 ago. 2017.

LOURO, G. L. Gênero, sexualidade e educação: uma perspectiva pós-estruturalista. Rio de janeiro: Vozes, 1997.

. Currículo, gênero e sexualidade. Porto: Porto Editora, 2000. 
(Org.). O corpo educado. Belo Horizonte: Autêntica, 2001.

MAZZON, J. A. (Coord.). Projeto de estudo sobre ações discriminatórias no âmbito escolar: sumário dos resultados da pesquisa. São Paulo: MEC; INEP; FIPE, 2009.

MISKOLCI, R. Um corpo estranho na sala de aula. In: ABRAMOWICZ, A.; SILVÉRIO, V. R. (Org.). Afirmando Diferenças: montando o quebra cabeça da diversidade da escola. Campinas: Papirus, v. 1, p. 13-26, 2005.

OLIVEIRA, I. B. de. Currículos praticados: entre a emancipação e a regulação. Rio de Janeiro: DP\&A, 2003.

PRADO, M. A.; MACHADO, F. V. Preconceitos contra homossexualidades: a hierarquia da invisibilidade. São Paulo: Cortez, 2008.

SACRISTÁN, J. G. O currículo uma reflexão sobre a prática. Porto Alegre: Artmed, 2000.

SCOTT, J. W. Gênero: uma categoria útil de análise histórica. Educação \& Realidade. Porto Alegre, v. 20, n. 2, p. 71-99, jul./dez. 1995.

SILVA, T.T. Desconstruindo o construtivismo pedagógico. Educação \& Realidade, Porto Alegre, v. 18, n. 2, p. 3-10, jul./dez. 1993.

. Teorias do currículo: uma introdução crítica. Porto: Porto Editora Ltda, 2000.

. Documentos de Identidade: uma introdução às teorias do currículo. 3 ed. $1^{\text {a }}$ reimp. Belo Horizonte: Autêntica, 2010.

. Currículo e identidade social: territórios contestados. In: . (Org.). Alienígenas na sala de aula. Petrópolis: Vozes, 2011.

WEEKS, J. O corpo e sexualidade. In: LOURO, G. L. (Org.). O corpo educado: pedagogias da sexualidade. Belo Horizonte: Autêntica, 2000.

Samira de Moraes Maia Vigiano: Doutoranda em Educação, tutora presencial do curso de Especialização em Gênero e Diversidade na Escola, orientadora pedagógica do Programa Institucional de Apoio Pedagógico aos Estudantes de Graduação da Universidade Federal de Santa Catarina (UFSC). Bolsista FUMDES/UNIEDU/SC.

E-mail: samirammvigano@gmail.com

Maria Hermínia Lage Fernandes Laffin: Professora Pós-Doutora do Departamento de Metodologia de Ensino e do Programa de Pós- Graduação em Educação da Universidade Federal de Santa Catarina (PPGE/UFSC). Subcoordenadora do PPGE.

E-mail: herminialaffin@gmail.com 
